\title{
Habitat, human pressure, and social behavior: Partialling out factors affecting large-scale territory extinction in an endangered vulture
}

\author{
Martina Carrete ${ }^{\mathrm{a}, *}$, Juan M. Grande ${ }^{\mathrm{a}}$, José L. Tella ${ }^{\mathrm{a}}$, José A. Sánchez-Zapata ${ }^{\mathrm{b}}$, \\ José A. Donázar ${ }^{\mathrm{a}}$, Ricardo Díaz-Delgado ${ }^{\mathrm{a}}$, Alfredo Romo ${ }^{\mathrm{c}}$ \\ ${ }^{a}$ Department of Applied Biology, Estación Biológica de Doñana (CSIC), Avda. M. Luisa s/n, 41013 Sevilla, Spain \\ ${ }^{\mathrm{b}}$ Department of Applied Biology, University Miguel Herná ndez, Ctra. Beniel km 3.2, 33012 Orihuela, Alicante, Spain \\ ${ }^{\mathrm{c}}$ Remote Sensing Laboratory - LATUV, Faculty of Sciences, University of Valladolid, 47071 Valladolid, Spain
}

Keywords:

Conservation behavior

Deviance and hierarchical

partitioning

Extinction

Habitat suitability

Neophron percnopterus

Poisoning
A B S T R A C T

Extinctions are often the result of multiple factors that are difficult to disentangle and so methods for identifying simple and combined types of extinctions are valuable for both basic and applied ecology. We applied a modification of variance partitioning and a hierarchical partitioning analysis to test several hypotheses that attempt to explain the recent large-scale disappearance of Egyptian Vulture breeding territories in Spain. Our aim was to identify and then separate the simple (or pure) from the combined effects of habitat features, human pressure, and the social behavior of the species on the risk of extinction from a territory while controlling for spatial autocorrelation. Deviance partitioning showed that a complex mix of factors is significantly related to the disappearance of more than 400 territories throughout Spain. Abandoned territories were located in areas that are isolated from other conspecific territories and far from communal roost sites. In addition, these territories were found in places where there is a lack of natural habitats, high habitat fragmentation and reduced habitat diversity, and where food availability seems to be low and the illegal use of poison to control predators is a common practice. Deviance partitioning also showed an important spatial component in the probability of extinction. Abandoned territories were not randomly distributed; rather, they were aggregated in extinction 'hotspots', mainly related to food availability and human pressure. Deviance partitioning turned out to be an useful tool for identifying the relative contribution of a variety of factors - and their combined effects - associated with an extinction process. The deviance explained by each factor must be interpreted, however, in the context of a good knowledge of the life history of the species. Hierarchical partitioning can help rank conservation priorities and, by using as an objective criterion the relative weight of each independent variable that could be effectively managed for conservation, may provide wildlife managers with a means of saving funds and optimizing action plans.

(C) 2006 Elsevier Ltd. All rights reserved.

\footnotetext{
* Corresponding author: Tel.: +34 954232340 .

E-mail address: martina@ebd.csic.es (M. Carrete).
} 
1.

Introduction

Extinction is a complex problem and often occurs as a result of multiple interacting factors. Disentangling causes and predicting the risk of extinction are two of the main challenges currently facing conservation biology and resource management, and robust statistical techniques are still badly needed (Green et al., 2005). Logistic regressions and generalized linear modeling are often employed to deal with the presence/absence of a species with respect to environmental or habitat variables (Rushton et al., 2004). However, co-linearity between explanatory variables and spatial autocorrelation, two methodological and biological problems rarely taken into account, can hinder the detection of key factors underlying studied processes (Legendre and Legendre, 1998; Mac Nally, 2000, 2002). Recently, two approaches for tackling co-linearity problems occurring while quantifying variation associated with spatial patterns have been proposed. Variation partitioning is a quantitative method in which the variation in a dependent variable can be separated into independent components reflecting the relative importance of different groups of explanatory variables and their joint effects (Borcard et al., 1992). In addition, hierarchical partitioning provides estimates of the independent and joint explanatory capacities of each predictor variables by considering all possible models in a multivariate regression setting (Chevan and Sutherland, 1991; Mac Nally, 2000). Although these methods have been used for assessing the relative roles of environment and space in faunal and floral distributions (Borcard and Legendre, 1994; Maestre et al., 2003; Deckers et al., 2004; Titeux et al., 2004; Anadón et al., 2006), to our knowledge they have as yet been little used in conservation ecology (Souza et al., 2002; Corney et al., 2004; Gibson et al., 2004; Radford and Bennett, 2004; Banks et al., 2005).
Here, we take advantage of a large-scale survey of Egyptian Vultures Neophron percnopterus breeding in Spain to model the probability of territorial extinction using the abovementioned statistical tools. The populations of this long-lived bird have steadily declined over large parts of its European and African range during the 20th century. In peninsular Spain, where the bulk of its European breeding population is located (ca. 80\%; Donázar, 2004), 25\% of its territories were abandoned during the previous decade (Fig. 1) and the species is thus regarded as 'endangered' both in Spain (Donázar, 2004) and Europe (BirdLife International, 2004). Although several hypotheses have been proposed to explain this decline (see reviews in Donázar, 2004), quantitative evaluations are scarce and have been only carried out for small populations (Liberatori and Penteriani, 2001; Sarà and De Vittorio, 2003). A fine-scale analysis accounting for spatial autocorrelation and the social behavior of the species (see below) is needed to ascertain the causes of territorial extinction and to guide effective conservation programs.

The objective of this study was thus to establish the relative importance of habitat features, human pressure, and social behavior in the recent abandonment of many Egyptian Vulture territories in peninsular Spain. Habitat transformation is one of the main extrinsic causes of the loss of biodiversity worldwide (Diamond, 1989) and has been mentioned as a potential threat for Spanish vultures (Donázar, 1993). However, many transformed landscapes provide suitable habitats for species tolerant to human disturbances and so an effective conservation program for a given species needs to clearly understand its plasticity with regard to habitat changes. Human pressure through disturbance or direct interaction may seriously affect population densities and trends. Although human pressure may take many forms and can affect all ages, direct persecution (e.g.,

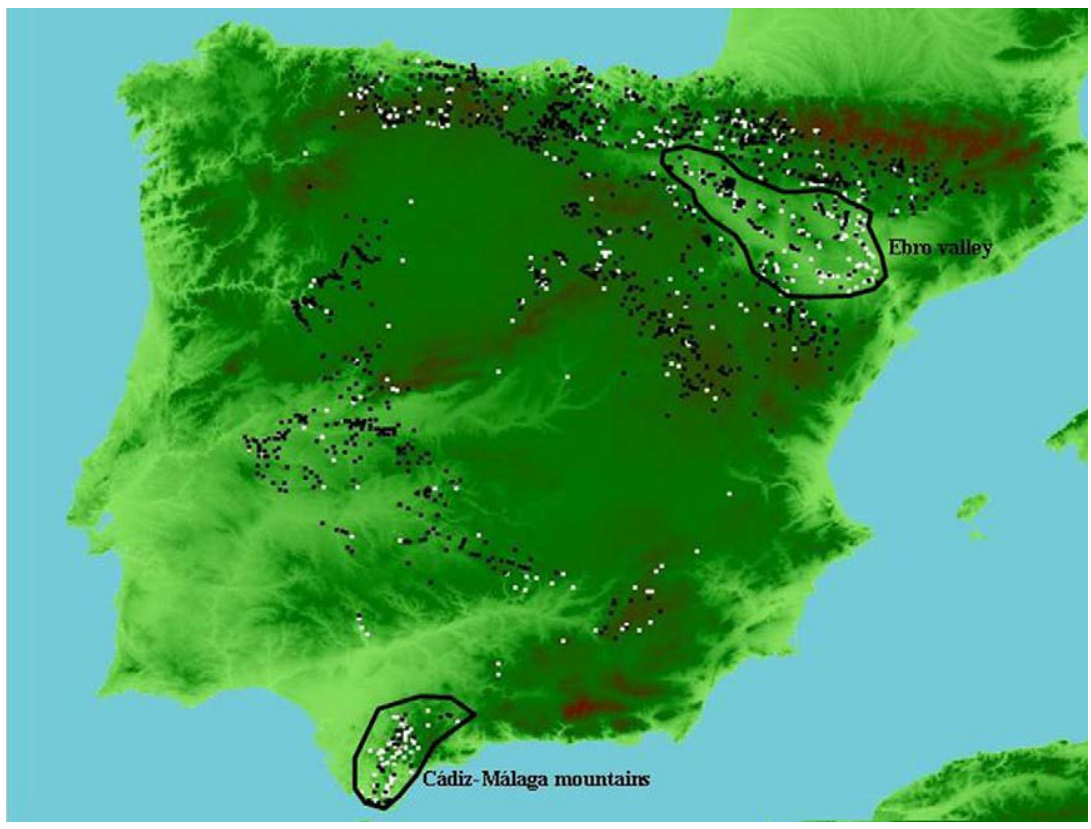

Fig. 1 - Distribution of occupied (black points) and extinct (white points) territories of Egyptian vulture in peninsular Spain in 2000 (redrawn from del Moral and Martí, 2002). Two long-term monitored subpopulations (see Fig. 2) are shown as Ebro Valley and Cádiz-Málaga mountains. 
trapping, shooting and poisoning) causing the death of breeders is one of the main anthropogenic factors underlying population declines in large species such as many raptors with low reproductive rates and delayed maturity (Newton, 1998). Furthermore, persecution can provoke local extinctions and disappearances from habitats otherwise suitable for occupation (Villafuerte et al., 1998; Carrete et al., 2002; Whitfield et al., 2004). In spite of its strong connection with population dynamics and animal conservation, behavior has seldom been taken into account in models of extinction and species-habitat relationships (Reed, 1999). The use of conspecifics as cues during the habitat selection process is a widespread strategy that may promote animal aggregations at traditionally occupied sites (Serrano et al., 2004; Sergio and Penteriani, 2005). On the other hand, antagonistic interactions between neighbors may preclude territory establishment, since high intraspecific densities may increase competition for resources (Newton, 1998; Carrete et al., 2006; Serrano and Tella, 2007). Hence, behavioral constraints may also separate habitat suitability from its attractiveness for occupation through both positive and negative interactions affecting specieshabitat relationships.

We used all known Egyptian Vulture breeding territories in peninsular Spain (1279 occupied and 433 extinct; Fig. 1) to perform a modified version of the variation partitioning analysis proposed by Borcard et al. (1992), in which we decomposed the total deviance explained by generalized linear models into components of habitat, conspecific presence, and human pressure. Significant models within each group were subject to a second deviance partitioning, separating the independent effects of predictor variables from spatial autocorrelation. Finally, we used a hierarchical partitioning analysis to rank conservation priorities, using as an objective criterion the independent contribution of each variable to explain territorial extinction.

\subsection{Modeled species}

The Egyptian Vulture is a medium-sized, cliff-nesting, transSaharan migrant raptor that defends long-term established territories during the breeding season. Most territories hold a single nest (rarely 2-3 nests situated in the same or adjacent cliffs) that is occupied year after year over long periods of time. The long-term monitoring of marked birds (authors, unpubl. data) shows that territories are reoccupied every year in early March by their previous owners or, when one of them dies, by a replacement bird. The dispersal of breeders is rare (only in $7.5 \%$ of 203 breeding attempts did one of the birds change territory). In the few areas where species numbers have recovered, most of territories consist of recolonizations of vacant territories (the so-called extinct territories referred to throughout the text). Therefore, territorial extinctions occur not as a result of breeder dispersal, but because an external cause has affected the territory owners and/or the territorial 'attractiveness' for recruitment.

Despite being a territorial breeder, this species may forage and roost socially. This is especially true for non-breeding birds, which also migrate to and from Europe and gather in communal roosts during the breeding season. These roost sites are located near predictable food sources such as rubbish dumps or muladares (places traditionally used by farmers for dumping dead livestock) may comprise of up to two hundred birds in pre-adult ( $<4$ years old) and adult plumage (Donázar et al., 1996a).

\section{Methods}

\subsection{Monitoring data}

We used the results of the 2nd Spanish Survey of the Egyptian Vulture performed by more than 600 experienced local ornithologists during 2000 (del Moral and Martí, 2002). All

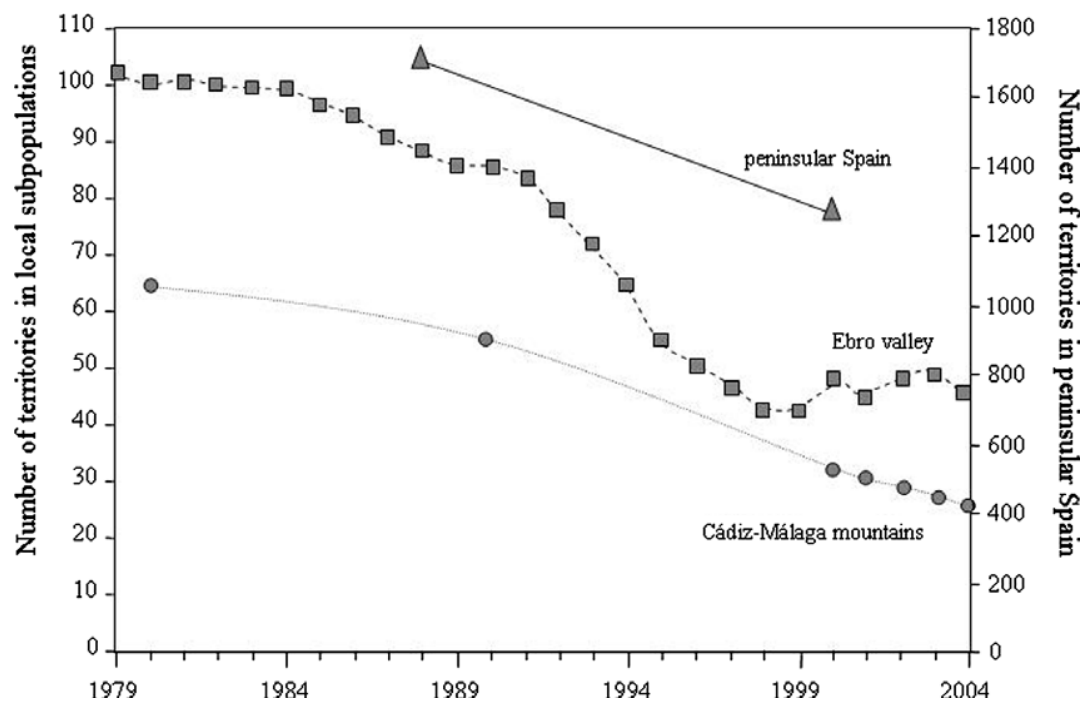

Fig. 2 - Population trends for the whole population of Egyptian vulture in peninsular Spain and for two long-term monitored populations shown in Fig. 1: Ebro Valley (a), and Cádiz-Málaga mountains (b). Years of monitoring are pointed with solid symbols. 
territories known to have been occupied by the species in the late 1980s (Perea et al., 1990) were visited at least three times for a minimum of $3 \mathrm{~h}$ (Braillon, 1979, 1987) during the mating, incubation, and nestling periods. This methodology was applied on a national scale after its usefulness for detecting the loss of breeding territories was proven during the longterm monitoring of two Egyptian Vulture subpopulations (see Fig. 2; authors, unpubl. data).

We considered that a territory was occupied when either territorial birds or occupied nests were observed. Otherwise, we classified the territories as extinct. It is worth noting that the term extinction is usually reserved for populations or subpopulations. However, when the overall population viability of a territorial species depends more on within-patch (birth and death) than between-patch dynamics (immigration and emigration), the individual territory can be identified as a suitable unit of habitat (Carrete et al., 2005). In our particular case, besides, the long-term monitoring of this declining species (Fig. 2) shows that in some areas such as the mountains of Cádiz-Málaga no empty territories have been recolonized since at least $1980(\mathrm{n}=40$; authors, unpubl. data). In addition, more than $70 \%(n=119)$ of vacant territories of another sub- population located in the Ebro valley have remained unoccupied for at least 7 years (range: 7-30 years), with only some recolonizations $(\mathrm{n}=32)$ taking place in a mean time of 3 years (authors, unpubl. data). Taking into account this information, we are confident of using the term 'extinction' to refer to a vacant territory, at least in light of current population trends. Below we discuss the results taking into account the potential biases arising from differences between long-term (extinct) and short term (temporary loss of a breeding pair) vacant territories (see Section 4).

\subsection{Explanatory variables}

\subsubsection{Habitat}

We fixed circular plots with a radius of 1 and $8 \mathrm{~km}$ around the nest-site of each territory to measure habitat variables at two spatial scales. These radii correspond, respectively, to the core area and the home range of breeding Egyptian Vultures radiotracked in southern Spain (authors, unpubl. data). Habitat variables were grouped into three main categories: (a) relief and land-use, (b) landscape structure, and (c) food availability (Table 1).

\section{Table 1 - Variables used to describe occupied and extinct territories of Egyptian vulture}

\section{Habitat}

(a) Relief and land-use cover

SLO Mean slope (in degrees)

IRR Irregularity index, measured as the standard deviation of the slope within the core area (ca) or the home range (hr) (in degrees)

EAG Proportion of the core area (ca) or the home range (hr) covered by extensive agriculture (cereals, almonds, olives,...)

IAG Proportion of the core area (ca) or the home range (hr) covered by intensive agriculture (vegetable crops, oranges, maiz...)

AGR Proportion of the core area (ca) or the home range (hr) covered by agriculture (intensive and extensive)

FOR Proportion of the core area (ca) or the home range (hr)covered by forests (mainly Pinus sp.)

OPE Proportion of the core area (ca) or the home range (hr) covered by open lands (shrubs, grass, ...)

MIX Proportion of the core area (ca) or the home range (hr) covered by mixed forests

NAT Proportion of the core area (ca) or the home range (hr) covered by natural vegetation (open and forested lands)

(b) Landscape structure

NPA Number of habitat patches of any cover type in the core area (ca) or the home range (hr)

RIC Number of different land cover classes in the core area (ca) or the home range (hr)

EDG Total edge length of all habitat patches of any cover type in the core area (ca) or the home range (hr) (in km)

DIV Habitat diversity in the core area (ca) or the home range (hr) measured using the Shannon-Weaver index ( - R $\mathrm{p}_{\mathrm{i}}$ log $\mathrm{p}_{\mathrm{i}}$ ), and including all habitat patches of any cover type

(c) Food availability

PPI Primary productivity index

COW Number of cows in the core area (ca) or the home range (hr)

GOA Number of goats in the core area (ca)or the home range (hr)

SHE Number of sheep in the core area (ca) or the home range (hr)

PIG Number of pigs in the core area (ca) or the home range (hr)

CAT Number of cattle (cows + goat + sheep + pig) in the core area (ca) or the home range (hr)

DMU Distance to the nearest "muladar" (in $\mathrm{km}$ )

Conspecific presence

DOT Distance to the nearest occupied territory of Egyptian vulture (in $\mathrm{km}$ )

SOT Isolation of the territory with respect to the other occupied ones

DRS Distance to the nearest conspecific roost site (in $\mathrm{km}$ )

Human pressure

DP Distance to the nearest inhabited village (in $\mathrm{km}$ )

DI Number of inhabitants in the core area (ca) or the home range (hr)

URB Proportion of the core area (ca) or the home range (hr) covered by urban areas

POI Number of poisoning episodes in the core area (ca) or the home range (hr)

Habitat and some human pressure variables were measured at two scales, the core area and the home range (1 and 8 km radius around the nest, respectively). 
Relief variables were derived from a digital elevation model (DEM) with a spatial resolution of $100 \mathrm{~m}$. The proportions of the different land-use types, as well as the landscape structure descriptors, were obtained from the CORINE Land Cover database (CEC, 1991), a general-purpose land-cover map of Europe useful for building broad habitat models of bird distribution (Seoane et al., 2003).

Dietary studies have shown that Egyptian Vultures feed on carcasses of both cattle and small wild animals, the respective contribution of each to diet depending notably on availability (Donázar, 1993). Thus, we estimated food availability as the cattle density within the home range during 2000 (Instituto Nacional de Estadísticas), as well as the distance from the territory to the nearest muladar. As well, we also considered the Primary Productivity Index (PPI), an estimator of primary productivity (Seoane et al., 2003) that indirectly assesses the availability of natural prey. This index, derived from a composite monthly maximum value of NDVI images from the sensor AVHRR on the NOAA satellites was the most important component (95.8\% of explained variability in data) of a principal component analysis performed with NDVI images dating from between 1986 and 2000 (Seoane et al., 2003).

\subsubsection{Conspecific presence}

Both intraspecific competition and conspecific attraction were included by calculating the linear distance from the nest-site in question to the nearest occupied territory $\left(\mathrm{nnd}_{\mathrm{i}}\right.$ ) and by producing an isolation index $\left(\mathrm{S}_{\mathrm{i}}\right)$ describing the relative position of a pair within the spatial distribution of all other pairs (Carrete et al., 2006). This latter index, whose values are negatively related to isolation (range: $0-1$, from more isolated to more connected), was defined by $S_{i}=\exp \left(-d_{i j}\right)$ (with i $5 \mathrm{j}$ ), where $d_{i j}$ was the linear distance between pairs $i$ and $j$, and with $\mathrm{j}$ representing all known territories. Thus, while $n_{n d}$ may reflect direct interactions between neighbors, $S_{i}$ describes the social environment in which a territory is situated (Carrete et al., 2006).

Since communal roosts may encourage mating between non-breeding birds and thus territorial acquisition in the surrounding area (Blanco and Tella, 1999), we also calculated the linear distance from each territory to the nearest roost site as a variable of social behavior that might affect the persistence of breeding territories. The location of communal roosts was taken from previous studies (Donázar et al., 1996a, authors, unpubl. data).

\subsubsection{Human pressure}

Raptors are often sensitive to human activities around their nesting areas. We used the density of population and the distance to the nearest urban settlement as measures of human presence and activity.

Accurate data on the incidence of poisoning are difficult to obtain (Blanco and Montoya, 2004; Whitfield et al., 2003). Therefore, we used all the available information (poisonings of birds confirmed by toxicological analyses) for Spain collected as part of the Antidoto Program, a national campaign coordinated by WWF-ADENA. As a measure of poisoning pressure, we obtained the total number of poisoning episodes registered in the municipal districts included in Egyptian Vul- ture territories from 1990 (when poisoning data records began) to 2000. These included Egyptian Vultures, other raptors, corvids, and carnivores ( $n=6.15$ events). These records may be biased by different degrees of awareness and/ or openness regarding poisoning; nevertheless, they provide the only way of quantitatively assessing the impact of poisoning on a national scale.

\subsection{Statistical analysis}

\subsubsection{Conceptual model of deviance partitioning}

We used three main groups of explanatory variables to explain territorial extinctions: habitat, conspecific presence, and human pressure. However, as habitat is a wide-ranging concept, we divided it into three sub-groups: relief and land-use, food availability, and landscape structure. Aside from its conceptual interest, this two-step analysis is useful since analytical procedures for deviance partitioning become complex when more than three groups of variables are used. The first step (Step 1; Fig. 3) separates within the habitat group the pure effects of (a) relief and land-use, (b) food availability, and (c) landscape structure, as well as the combined variability of the joint effects of (d) relief and land-use and landscape structure, (e) relief and land-use and food availability, (f) food availability and landscape structure, and (g) relief and landuse, food availability, and landscape structure. Then, in Step 2 (Fig. 3) we derive the following fractions: $\left(a^{0}\right)$ the pure effect of habitat variables (i.e. relief and land-use, food availability, and landscape structure), $\left(b^{0}\right)$ the pure effect of conspecific presence, $\left(c^{0}\right)$ the pure effect of human pressure; and the joint effect of $\left(\mathrm{d}^{0}\right)$ habitat and human pressure, $\left(\mathrm{e}^{0}\right)$ habitat and conspecific presence, $\left(\mathrm{f}^{0}\right)$ conspecific presence and human pressure, and $\left(\mathrm{g}^{0}\right)$ habitat, conspecific presence, and human pressure.

\subsubsection{Modeling procedure}

The probability that a territory had become extinct was described mathematically by means of generalized linear models (GLM) using the logistic (0: occupied territories, 1: extinct territories) as a link function and the binomial as an error distribution (McCullagh and Nelder, 1989). Forward stepwise procedures were performed separately to exclude within each group variables that did not contribute significantly $(p>0.05)$ to explaining extinction. Both the linear and the quadratic forms of the variables were considered when they had a biological meaning. For each significant model, we calculated both the percentage of deviance explained and Akaike's Information Criterion (AIC) for a straightforward modeling selection within each group of variables (i.e., habitat-relief and land-use, food availability, and landscape structure-, conspecific presence, and human pressure). The first of these two values is a measurement of the amount of variation explained by the variables included in a model, while the second is commonly used to rank alternative models (models within 2AIC units of the selected one are commonly considered as alternatives). All models were performed with the R 2.0.1 program (R Development Core Team, 2004).

Due to spatial autocorrelation, values for neighboring sites may be more similar than they would be for a random set of observations (Legendre and Legendre, 1998) and so we 

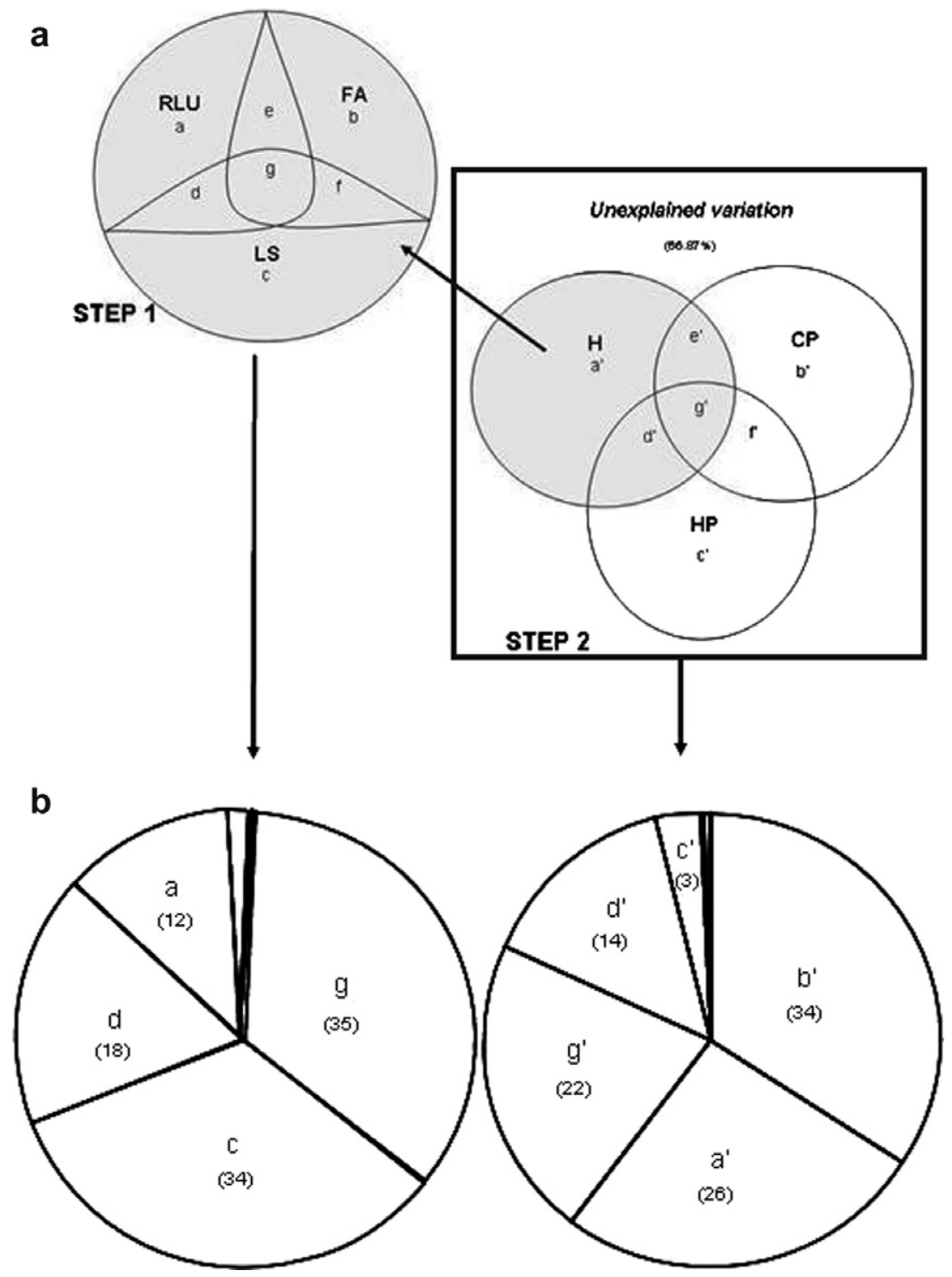

Fig. 3 - (a) Two-step deviance partitioning analysis for the probability of extinction of a breeding territory of Egyptian vulture. In the first step, deviance is explained by relief and land-use (RLU), food availability (FA), and landscape structure (LS) variables. In the second step, deviance is explained by habitat $(\mathrm{H}=$ relief and land-use + food availability + landscape structure), conspecific presence (CP), and human pressure (HP) variables. (b) Percentage of deviance explained (in brackets) by each component of the partition (numbers are rounded).

corrected for this effect in the extinction process by including in every model a spatial term of the form $b_{1} x+b_{2} y+b_{3} x^{2}+b_{4-}$ $x y+b_{5} y^{2}+b_{6} x^{3}+b_{7} x^{2} y+b_{8} x y^{2}+b_{9} y^{3}$. This cubic trend surface ensures not only that linear gradient patterns will be extracted, but also that more complex features such as patches or gaps, which require quadratic and cubic terms to be correctly described, will also be extracted (Legendre and Legendre, 1998).

\subsubsection{Deviance and hierarchical partitioning procedures}

Assuming that the deviance explained by a model is a good measure of the variability in the data set explained by the variables included, we performed a series of models (see Section 2.3.2) to isolate all the components needed for partitioning.
First, we obtained the relief and land-use (RLU), food availability (FA), landscape structure (LS), conspecific presence (CP), and human pressure (HP) models. The habitat (H) model was obtained by combining all the variables selected in the relief and land-use, food availability, and landscape structure models (Step 1; Fig. 3). Then, six models were performed in which the joint effect of two groups of variables were considered at the same time: relief and land-use and food availability (RLU + FA), relief and land-use and landscape structure $(\mathrm{RLU}+\mathrm{LS})$, food availability and landscape structure (FA + LS), habitat and conspecific presence $(\mathrm{H}+\mathrm{CP})$, habitat and human pressure $(\mathrm{H}+\mathrm{HP})$, and conspecific presence and human pressure $(\mathrm{CP}+\mathrm{HP})$. Finally, we regressed the dependent variable with all previously selected variables (i.e., variables retained as significant in models) together to obtain two general mod- 
els that summarized the total deviance explained in the data set during each step (Step 1: RLU + FA + LS, and Step 2: $\mathrm{H}+\mathrm{CP}+\mathrm{HP})$. The remaining components were calculated using simple equation systems. The deviance explained by each of the previous models was calculated as the percentage of the total deviance explained by the respective general model (Step 1: DRLU + FA + LS and Step 2: DH + CP + HP).

Using the hier.part package (Mac Nally and Walsh, 2004) from the R 2.0.1 program (R Development Core Team, 2004), we performed a hierarchical partitioning analysis including only those variables retained as significant in previous models that could be changed by management policies. Since this process involved calculating the increase in the fit of all possible models with a particular variable compared with the increase without that variable (Mac Nally, 2002), it allowed us to identify those variables with an important independent - not partial - correlation with a dependent variable and compare them with those that have little independent effect on that dependent variable. The percentage of independent effect was used as a criterion for ranking and deriving conservation priorities.

\section{Results}

3.1. Factors affecting territorial extinction: logistic regressions and deviance partitioning

The variables retained by regression models as statistically significant (Table 2) made it clear that extinct Egyptian Vulture territories are located in flat areas (IRR), with low natural vegetation (NAT) and extensive agriculture (EAG) coverage. These sites are characterized by a low diversity of habitats (DIV), which are also highly fragmented (NPA). The response of the extinction probability to these two last variables flattened out after reaching the threshold values and thus fits the quadratic function better. Moreover, primary productivity (PPI) was lower in extinct than in occupied territories. Taking into account their relative positions within the whole population, the extinct territories were isolated from conspecific breeding pairs (SOT) and far away from communal roost sites (DRS). As well, the high number of poisoning events (POI) registered in the surroundings of extinct territories shows that this illegal practice was usual in these places. It is worth noting that all variables retained by the models were measured in the home range and not in the core area. No alternative models were found.

Together, habitat models (i.e. RLU, FA, and LS models, Step 1; Fig. $3 b$ ) explained $20.73 \%$ of the deviance in the data set, a figure that increases to $33.13 \%$ when conspecific presence and human pressure variables are also considered (Step 2; Fig. 3b). Among habitat components (Step 1; Fig. 3b), the joint effect of relief and land-use, food availability, and landscape structure ( $g=35 \%$ of the total deviance explained), the pure effect of landscape structure (c=34\%), the combined effect of relief and land-use and landscape structure $(d=18 \%)$, and the pure effect of relief and land-use $(a=12 \%)$ were the most representative and together accounted for more than $97 \%$ of the explained deviance. The remaining $(<3 \%)$ was explained by components $\mathrm{b}$, e, and $\mathrm{f}(0.42 \%, 1.54 \%$, and $0.17 \%$, respectively). Of the total deviance explained in the second step (Step 2; Fig. 3b), the most important components were the pure effects of conspecific presence $\left(b^{0}=34 \%\right)$ and habitat $\left(a^{0}=26 \%\right)$, followed by the joint effect of the group of the three variables together (habitat, conspecific presence, and human pressure, $g^{0}=22 \%$ ), the joint effect of habitat and human pressure $\left(d^{0}=14 \%\right)$, and the pure effect of human pressure $\left(c^{0}=3 \%\right)$. Deviance explained by other components $\left(\mathrm{e}^{0}\right.$ and $\left.\mathrm{f}^{0}\right)$ was negligible $(<1 \%)$.

The spatial term accounted for a variable proportion of variability in data, being very important for the food availability and human pressure models (91\% and $82 \%$, respectively; Fig. 4). For the other models, the spatial component explained between $29 \%$ and $50 \%$ of variability in territorial extinction (Fig. 4).

Table 2 - Generalized linear models obtained for the probability of extinction of a breeding territory of Egyptian vulture in peninsular Spain

\begin{tabular}{|c|c|c|c|c|c|}
\hline & Variables & Estimate & SE & $\mathrm{Z}$ & $\mathrm{p}$ \\
\hline \multicolumn{6}{|l|}{ Habitat } \\
\hline \multirow[t]{3}{*}{ Relief and land uses } & NAT & -3.64 & $4.38 \mathrm{E}^{-1}$ & -8.30 & $<0.001$ \\
\hline & IRR & $-2.29 \mathrm{E}^{-1}$ & $5.17 \mathrm{E}^{-2}$ & -4.42 & $<0.001$ \\
\hline & EAG & -1.92 & $5.16 \mathrm{E}^{-1}$ & -3.72 & $<0.001$ \\
\hline \multirow[t]{4}{*}{ Landscape structure } & DIV & -2.09 & $3.92 \mathrm{E}^{-1}$ & -5.32 & $<0.001$ \\
\hline & $\mathrm{DIV}^{2}$ & $2.74 \mathrm{E}^{-1}$ & $7.75 \mathrm{E}^{-1}$ & 3.53 & $<0.001$ \\
\hline & NPA & $1.56 \mathrm{E}^{-2}$ & $4.64 \mathrm{E}^{-3}$ & 3.35 & $<0.001$ \\
\hline & $\mathrm{NPA}^{2}$ & $-3.29 \mathrm{E}^{-5}$ & $1.25 \mathrm{E}^{-5}$ & -2.64 & $<0.001$ \\
\hline Food availability & PPI & $-2.29 \mathrm{E}^{-3}$ & $6.15 \mathrm{E}^{-4}$ & -3.73 & $<0.001$ \\
\hline \multicolumn{6}{|l|}{ Conspecific presence } \\
\hline & SOT & -19.6 & 2.49 & -7.93 & $<0.001$ \\
\hline & DRS & $9.35 \mathrm{E}^{-11}$ & $2.62 \mathrm{E}^{-11}$ & 3.57 & $<0.001$ \\
\hline \multicolumn{6}{|l|}{ Human pressure } \\
\hline & POI & $1.75 \mathrm{E}^{-2}$ & $3.57 \mathrm{E}^{-3}$ & 4.89 & $<0.001$ \\
\hline
\end{tabular}




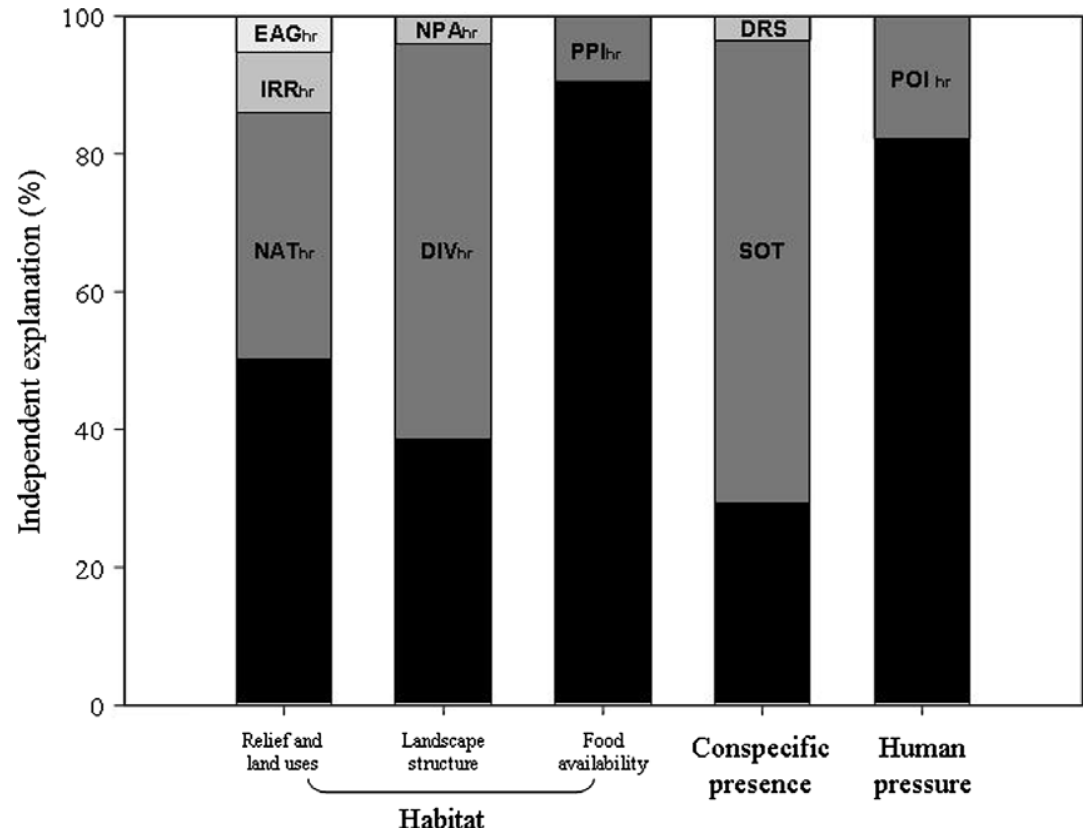

Fig. 4 - Results of the deviance partitioning analysis performed to asses the independent contribution of the explanatory variables included in models. In black, deviance explained by the spatial pattern of the territories.

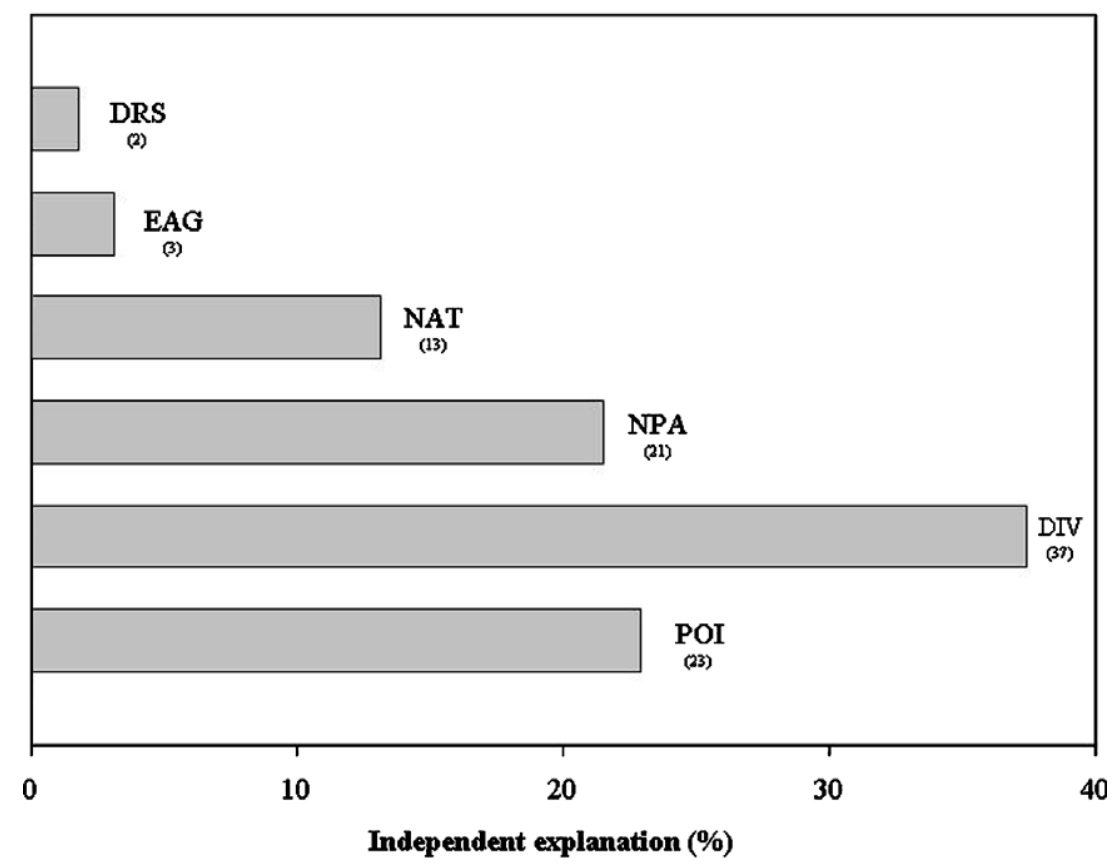

Fig. 5 - Management actions for the Egyptian vulture in peninsular Spain derived from hierarchical partitioning. In brackets, $\%$ of independent variability explained. EAG: proportion of the home range covered by extensive agriculture, NAT: proportion of the home range covered by natural vegetation, DIV: diversity of land uses within the home range, NPA: number of habitat patches in the home range, POI: number of poisoning episodes in the home range, DRS: distance to the nearest conspecific roost site.

\subsection{Conservation priorities: hierarchical partitioning analysis}

Of all the variables retained by the models to explain the probability of extinction (Table 2), only a few could feasibly be managed for conservation. Therefore, we only included in the hierarchical partitioning analysis diversity (DIV) and number of habitat patches (NPA), the proportion of natural vegetation (NAT) and extensive agriculture (EAG), the number of poisoning events (POI), and the distance to roost sites 
(DRS). Taking into account the percentages of the independent explanations (Fig. 5), any conservation proposal should highlight the need to maintain a diversity of land uses (37\%) with mainly natural vegetation (13\%) and extensive agriculture (3\%) and emphasize the importance of reducing habitat fragmentation (21\%). Furthermore, poisoning events (23\%) must be completely eliminated. Although their relative importance seems to be fairly small (2\%), it would also be desirable to maintain communal roost sites and even to promote the formation of new ones.

\section{4.}

\section{Discussion}

4.1. Factors affecting territorial extinction: the usefulness and limitations of deviance partitioning

Extinction processes are often the result of interacting effects that are difficult to disentangle and so methods to identify pure and combined types of extinctions are valuable in both basic and applied ecology. In a similar way to the variation partitioning proposed by Borcard et al. (1992), our deviance partitioning method takes advantage of generalized linear models to treat biological data and extend its use by means of a deviance partitioning framework. Here, we have shown that deviance partitioning is an useful tool for identifying the importance of a variety of factors and their combined effects in a extinction process. The relative contribution of each effect, described in terms of its explained deviance, must, however, be interpreted with caution and be backed up by a good knowledge of the life history of the species in order to correctly understand emergent relationships and to infer potential causes. In our study model, the definition of extinct territories mixes two associated processes (extinction and recolonization) that must be taken into account when interpreting the deviance partitioning results. As previously mentioned, the Egyptian Vulture is a site-tenacious, long-lived monogamous bird and so variables that are linked to the simultaneous death of both members of a breeding pair should be considered as the primary cause of territorial abandonment. After that, the intrinsic features of the territory, such as its habitat suitability and proximity to conspecific territories, may facilitate territorial recolonization (thus resulting in only a short-term vacancy) or, on the contrary, a long-term vacancy (and thus extinction). For conservation purposes, it is pivotal to clearly differentiate causes promoting extinction from causes that prevent or impair recolonization.

Despite the difficulties involved in recording accurate information, the illegal use of poison was significantly associated with the risk of extinction and this form of indirect human persecution could be the main cause of the fast population decline of the Egyptian Vulture (del Moral and Martí, 2002). Although poisoning events alone poorly explained territorial extinction, the high explanatory power of its combination with habitat traits seems to indicate that intense poisoning occurred in regions with natural vegetation and extensive agriculture that are suitable for small game such as European rabbits Oryctolagus cuniculus and red-legged partridges Alectoris rufa. In fact, $80 \%$ of the poisoning events were recorded in small game exploitations (Villafuerte et al., 1998). Although the use of small poisoned baits or carcasses is usually designed to eradicate mammalian predators such as foxes Vulpes vulpes, this practice affects the Egyptian Vulture and other opportunistic raptors that are especially susceptible to poisoning (Villafuerte et al., 1998; Blanco and Montoya, 2004; Whitfield et al., 2004). The sharp and generalized decline in the populations of some of these endangered species clearly points to the need to implement urgent measures aimed at tackling this human-predator-prey conflict (Villafuerte et al., 1998; Whitfield et al., 2003).

Some ecological processes may operate at population level as a result of behavioral decisions made by individuals. The important contribution of conspecific presence to the total deviance explained by our models suggests that philopatry and conspecific attraction, perhaps acting together, may be the most important factors affecting the probability of territorial persistence and thus highly relevant in conservation measures designed to avoid the loss of Egyptian Vulture territories. Dispersal distances are notably short for this large raptor (median: $17 \mathrm{~km}$ in males and $22 \mathrm{~km}$ in females; authors, unpubl. data) and dispersers seem to recruit into territories near their natal areas, thereby facilitating the replacement of dead mates and/or the recolonization of territories located within highly populated areas, and reinforcing the non-random pattern of territorial distribution at a national scale (Fig. 1). Although no further information is available for Egyptian Vultures, similar patterns in other species have also been explained by conspecific attraction (Forero et al., 2002; Etterson, 2003; Serrano and Tella, 2003). Isolated territories may be left unoccupied as a result of stochastic and/or demographic events and in the context of a philopatric species such as the Egyptian Vulture with low population densities, too many vacant territories could easily result in long-term extinction. Moreover, according to metapopulation theory (Hanski, 1999), the recent recolonization of a few extinct territories as well as the establishment of a few new nest sites (authors, unpubl. data), suggest that this process could be reversed if healthy source populations existed nearby.

The proximity to active territories and to communal roost sites demonstrates the important role played by social behavior in the likelihood of breeding territories being abandoned. Although correlatives, these results agree with the hypothesis that communal roosts may facilitate mating between nonbreeding birds and territorial acquisition in surroundings areas (Blanco and Tella, 1999). It is well known that communal roosts attract non-breeding Egyptian vultures from wide areas (Donázar et al., 1996a). Preliminary radio-tracking results indicate that most of the activities of these unpaired birds are centered on and around the roost sites and thus these sites may encourage pair formation, mate replacement, and territorial recolonization, as was found for another bird species with a similar social structure (Blanco and Tella, 1999).

Although food availability has traditionally been claimed as one of the most important factors limiting bird populations (Newton, 1998), we found little evidence of the role of this factor in the territorial extinction of Egyptian Vultures. This may be because our estimators of food availability are not good enough, or because our study species is highly opportunistic and may shift its diet according to available resources; it is a fact that its diet includes a significant proportion of wild prey such as small mammals, fish, reptiles, and birds (Donázar, 1993). 
The intrinsic productivity of an area, represented in our analysis by the PPI index, which may indirectly reflect the abundance of wild prey, does seem to be important in the longterm persistence of breeding territories. More importantly, the high percentage of deviance explained by the pure effect of landscape structure (c; Fig. 3b) and the joint effect of relief and land-use, landscape structure, and food availability (g; Fig. 3b) supports the idea that heterogeneous landscapes dominated by natural vegetation and extensive croplands, where food availability in terms of small wild prey (Angulo, 2003) and livestock carcasses (Donázar et al., 1996b) is high, may reduce the probability of long-term extinction in this species.

Our analyses suggest that, although they may be locally relevant (Donázar, 1993; Liberatori and Penteriani, 2001; Sarà and De Vittorio, 2003), muladares are not that important for maintaining breeding territories on a national scale. This result, however, should be treated with care. Firstly, the muladares recorded on a national scale are usually those that traditionally have a high availability of carrion and attract large numbers of Griffon Vultures Gyps fulvus; thus, the carrion provided by small cattle farms which, in turn, are preferred by Egyptian Vultures (Tella and Mañosa, 1993) may have been overlooked. Secondly, intensive landscape modifications are now rapidly eliminating landscape heterogeneity throughout Spain, a process that will certainly reduce the availability of wild prey; as well, livestock is increasingly being kept in stables and sanitary laws forbid the leaving of cattle carcasses in fields and force muladares to close (especially in light of the outbreak of Bovine Spongiform Encephalopathy in early 2000s; Tella, 2001). In this case, the existence of these predictable sources of food may play a major role in preventing breeding territories being abandoned in the near future. Moreover, muladares are a key strategy in the conservation of communal roosts, which support almost the whole non-breeding population of the species (Donázar et al., 1996a) and are, as discussed above, important for the maintenance of breeding territories. Deviance partitioning was unable to explain a large proportion of the variability in the data set. This may be a result of either the complex nature of our dependent variable, the lack of more detailed information regarding some of our explanatory variables (poisoning, food availability) at a more appropriate scale, or the absence of other potentially relevant factors such as (i) the presence and distribution of competitors such as Griffon Vultures Gyps fulvus and (ii) predators such as Eagle Owls Bubo bubo (Tella and Mañosa, 1993), or (iii) the existence of man-made structures including electric power lines (a factor responsible for the decrease of several threatened raptors and known to affect the Egyptian Vulture; Sergio et al., 2004; authors, unpubl. data) and wind farms (Barrios and Rodríguez, 2004; Guillemette and Larsen, 2002).

4.2. Use of deviance and hierarchical partitioning for establishing conservation guidelines

Deviance and hierarchical partitioning allowed us to extract important conclusions regarding conservation management. As well, deviance partitioning allowed us to separate in logistic models the independent contribution of explanatory vari- ables in the spatial distribution of territories. Although the spatial term included in our models only explained $7 \%$ of the total variability in the probability of extinction, it did account for a significant proportion of the deviance explained by models, ranging from ca. $30 \%$ of the conspecific presence model up to $90 \%$ of the variability explained by the food availability and human pressure models. This means that extinct territories are not randomly distributed in space, but rather are aggregated into extinction 'hotspots'.

The importance of the spatial component, as well as the fact that all the significant variables were measured at a home range scale, suggest that the conservation of the breeding population of Egyptian Vultures should be tackled at landscape rather than at a local scale. Some of the tools already being used include agro-environmental payments for the maintenance of low-intensity cultivation favoring the conservation of wildlife. Areas of traditional low intensity land-use in Spain, where cultivation interspersed with patches of natural vegetation form a highly diverse matrix, are a keystone in the conservation of this and many other threatened species (Tella et al., 1998; Blanco et al., 1998; Carrete and Donázar, 2005; current results).

Although the understanding of an ecological process requires an exhaustive analysis of all the potential factors involved, it is worth considering management actions that in fact only aim to palliate some of the problems facing the Egyptian Vulture. After performing a complete evaluation of the factors affecting territorial extinction, we found that of all the variables selected during modeling only a few could potentially be the object of management measures. These variables, submitted to a hierarchical partitioning analysis, showed a different priority order than when all variables retained by logistic regression models were taken into account. However, this allows us to rank conservation priorities using objective criteria such as the independent contribution of each variable in explaining variability in the extinction process. This statistical procedure could thus help managers save funds and maximize effective effort in the conservation of Egyptian Vultures and in work on other conservation problems where hierarchical partitioning can be easily applied.

\section{Acknowledgements}

We thank J.C. del Moral for access to the 2nd Spanish Survey of Egyptian Vultures and to all the participating voluntaries and wildlife rangers, especially O. Ceballos, A. Cortés, I. Luque, D. Serrano, M. de la Riva, J.R. Benítez, A. Camiña, D. Campió n, A. Margalida, E. Soto-Largo, G. Blanco, V. Hernández, A. Gil-Chamorro, A. Herrero, I. Zuberogoitia, F. Sánchez-Aguado, J.M. Canudo, A. Bueno, J.C. Albero, Boletas, C. Usieto, and M. Alcántara who provided additional information on roost sites and muladares. C. Cano gives all available information on poisoning events collected by ADENA. We thank very much J.D. Anadón for his invaluable help during data analysis, and F. Sergio and three anonymous referees for their comments on the article. M.T. Lockwood reviewed and improved the English version of the article. This study was partially supported by BBVA Foundation throughout its award for scientific research in conservation biology (2004). 
We dedicate this work to the late David Gómez Samitier, because of his devotion to the conservation of Egyptian vultures and other wildlife in Aragón.

R E F E R E N C E S

Anadón, J.D., Jimé nez, A., Martínez, M., Martínez, J., Pérez, I., Esteve, M.A., 2006. Factors determining the distribution of the spur-thighed tortoise Testudo graeca in south-east Spain: a hierarchical approach. Ecography 29, 339-346.

Angulo, E., 2003. Factores que afectan a la distribución y abundancia del conejo en Andalucía. PhD Thesis, Universidad Complutense de Madrid, Madrid, Spain.

Banks, S.C., Finlayson, G.R., Lawson, S.J., Lindenmayer, D.B., Paetkau, D., Ward, S.J., Taylor, A.C., 2005. The effects of habitat fragmentation due to forestry plantation establishment on the demography and genetic variation of a marsupial carnivore, Antechinus agilis. Biological Conservation 122, 581-597.

Barrios, L., Rodríguez, A., 2004. Behavioural and environmental correlates of soaring-bird mortality at on-shore wind turbines. Journal of Applied Ecology 41, 72-81.

BirdLife International, 2004. Birds in Europe: population estimates, trends and conservation status. Available from: http://www.birdlife.org/datazone/species/BirdsInEuropeII.

Blanco, G., Tella, J.L., 1999. Temporal, spatial and social segregation of red-billed choughs between two types of communal roost: a role for mating and territory acquisition. Animal Behaviour 57, 1219-1227.

Blanco, G., Montoya, R., 2004. Landscape muladares or poisoning? using GIS to assess factors behind decline of breeding red kites (Milvus milvus) in Spain. In: Rodríguez-Estrella, R.B.T. (Ed.), Spatial Analysis in Raptor Ecology and Conservation. CIBNOR, Mexico.

Blanco, G., Tella, J.L., Torre, I., 1998. Traditional farming and key foraging habitats for chough Pyrrhocorax pyrrhocorax in a Spanish pseudosteppe. Journal of Applied Ecology 35, 232-239.

Borcard, D., Legendre, P., 1994. Environmental control and spatial structure in ecological communities: an example using oribatid mites (Acari, Oribatei). Environmental and Ecological Statistics 1, 37-61.

Borcard, D., Legendre, P., Drapeau, P., 1992. Partialling out the spatial component of ecological variation. Ecology 73, 10451055.

Braillon, B., 1979. Le percnoptère dans les Pyré nées françaises, vol. 1. Cahiers Université Pau Pays de l'Adour, pp. 319-329.

Braillon, B., 1987. La nidification du vautour percnoptère Neophron percnopterus sur le versant nord des Pyrenées, un suivi d' ensemble commence il y a 27 ans. Acta Biologica Montana 7, 101-113.

Carrete, M., Donázar, J.A., 2005. Application of central place foraging theory shows the importance of Mediterranean dehesas for the conservation of the cinereous vulture, Aegypius monachus. Biological Conservation 126, 582-590.

Carrete, M., Sánchez-Zapata, J.A., Martínez, J.E., Sánchez, M.A., Calvo, J.F., 2002. Factors influencing the decline of a Bonelli's eagle Hieraaetus fasciatus population in southeastern Spain: demography, habitat or competition? Biodiversity and Conservation 11, 975-985.

Carrete, M., Sánchez-Zapata, J.A., Calvo, J.F., Lande, R., 2005. Demography and habitat availability in territorial occupancy of two competing species. Oikos 108, 125-136.

Carrete, M., Sánchez-Zapata, J.A., Tella, J.L., Moleón, M., GilSánchez, J.M., 2006. Components of breeding performance in two competing species: habitat heterogeneity, densitydependence, and parental age. Oikos 112, 680-690.
CEC, 1991. CORINE Land Cover. Commission of the European Communities: ECSC-EEC-EAEC, Brussels, Luxembourg.

Chevan, A., Sutherland, M., 1991. Hierarchical partitioning. The American Statistician 45, 90-96.

Corney, P.M., Le Duc, M.G., Smart, S.M., Kirby, K.J., Bunce, R.G.H., Marrs, R.H., 2004. The effect of landscape-scale environmental drivers on the vegetation composition of British woodlands. Biological Conservation 120, 491-505.

Deckers, B., Hermy, M., Muys, B., 2004. Factors affecting plant species composition of hedgerows: relative importance and hierarchy. Acta Oecologica 26, 23-37.

del Moral, J.C., Martí, R. (Eds.), 2002. El alimoche común en España y Portugal. I Censo Coordinado. Año 2000. Monografía n ${ }^{\circ} 8$. SEO/BirdLife. Madrid.

Diamond, J., 1989. Overview of recent extinctions. In: Western, D. Pearl, M. (Eds.), Conservation for the 21st Century. Oxford University Press, New York.

Donázar, J.A., 1993. Los Buitres Ibé ricos: Biología y Conservación. Ed. Reyero, Madrid.

Donázar, J.A., 2004. Alimoche Común, Neophron percnopterus. In: Madroño, A., González, C., Atienza, J.C. (Eds.), Libro rojo de las aves de España. Dirección General para la Biodiversidad / SEOBirdLife, Madrid, Spain.

Donázar, J.A., Ceballos, O, Tella, J.L., 1996a. Communal roosts of Egyptian vultures (Neophron percnopterus): dynamics and implications for the species conservation. In: Muntaner, J., Mayol, J. (Eds.), Biology and Conservation of Mediterranean Raptors. Monografía SEO-BirdLife. Madrid, Spain, pp. 189201.

Donázar, J.A., Naveso, M.A., Tella, J.L., Campión, D., 1996b. Extensive grazing and raptors in Spain. In: Pain, D., Pienkowski, M.W. (Eds.), Farming and Birds in Europe. Academic Press, London, pp. 117-149.

Etterson, M.A., 2003. Conspecific attraction in loggerhead shrikes: implications for habitat conservation and reintroductions. Biological Conservation 114, 199-205.

Forero, M.G., Donázar, J.A., Hiraldo, F., 2002. Causes and fitness consequences of natal dispersal in a population of Black kites. Ecology 83, 858-872.

Gibson, L.A., Wilson, B.A., Cahill, D.M., Hill, J., 2004. Spatial prediction of rufous bristlebird habitat in a coastal heathland: a GIS-based approach. Journal of Applied Ecology 41, 213-223.

Green, J.L., Hastings, A., Arzberger, P., Ayala, F.J., Cottingham, K.L., Cuddington, K., Davis, F., Dunne, J.A., Fortin, M.J., Gerber, L., Neubert, M., 2005. Complexity in ecology and conservation: mathematical, statistical, and computational challenges. Bioscience 55, 501-510.

Guillemette, M., Larsen, J.K., 2002. Postdevelopment experiments to detect anthropogenic disturbances: the case of sea ducks and wind parks. Ecological Applications 12, 868-877.

Hanski, I., 1999. Metapopulation Ecology. Oxford University Press, Oxford.

Legendre, P., Legendre, L., 1998. Numerical Ecology. Elsevier, Amsterdam.

Liberatori, F., Penteriani, V., 2001. A long-term analysis of the declining population of the Egyptian vulture in the Italian peninsula: distribution, habitat preference, productivity and conservation implications. Biological Conservation 101, 381389.

Mac Nally, R., 2000. Regression and model building in conservation biology, biogeography and ecology: the distinction between - and reconciliation of - "predictive" and "explanatory" models. Biodiversity and Conservation 9, 655671.

Mac Nally, R., 2002. Multiple regression and inference in ecology and conservation biology: further comments on identifying important predictor variables. Biodiversity and Conservation 11, 1397-1401. 
Mac Nally, R., Walsh, C.J., 2004. Hierarchical partitioning publicdomain software. Biodiversity and Conservation 13, 659-660.

Maestre, F.T., Cortina, J., Bautista, S., Bellot, J., Vallejo, R., 2003. Small-scale environmental heterogeneity and spatiotemporal dynamics of seedling establishment in a semiarid degraded ecosystem. Ecosystems 6, 630-643.

McCullagh, P., Nelder, J.A., 1989. Generalized Linear Models. Chapman \& Hall.

Newton, I., 1998. Population Limitation in Birds. Academic press, London.

Perea, J.L., Morales, M., Velasco, J., 1990. El alimoche (Neophron percnopterus) en España. Población, distribución, problemática y conservación. Icona, Colección Té cnica, Madrid.

R Development Core Team, 2004. R: A language and environment for statistical computing. R Foundation for Statistical Computing, Vienna, Austria. Available from: http://www.Rproject.org.

Radford, J.Q., Bennett, A.F., 2004. Thresholds in landscape parameters: occurrence of the white-browed treecreeper Climacteris affinis in Victoria, Australia. Biological Conservation 117, 375-391.

Reed, J.M., 1999. The role of behaviour in recent avian extinction and endangerment. Conservation Biology 13, 232-241.

Rushton, S.P., Ormerod, S.J., Kerby, G., 2004. New paradigms for modelling species distributions? Journal of Applied Ecology 41, 193-200.

Sarà, M., De Vittorio, M., 2003. Factors influencing the distribution, abundance and nest-site selection of an endangered Egyptian vulture (Neophron percnopterus) population in Sicily. Animal Conservation 6, 317-328.

Seoane, J., Viñuela, J., Díaz-Delgado, R., Bustamante, J., 2003. The effects of land use and climate on red kite distribution in the Iberian peninsula. Biological Conservation 111, 401-414.

Sergio, F., Penteriani, V., 2005. Public information and territory establishment in a loosely colonial raptor. Ecology 86, 340-346.

Sergio, F., Marchesi, L., Pedrini, P., Ferrer, M., Penteriani, V., 2004. Electrocution alters distribution and density of a top predator, the eagle owl Bubo bubo. Journal of Applied Ecology 41, 836845.

Serrano, D., Tella, J.L., 2003. Dispersal within a spatiallystructured population of lesser kestrels: the role of spatial isolation and conspecific attraction. Journal of Animal Ecology 72, 400-410.

Serrano, D., Tella, J.L., 2007. The role of despotism and heritability in determining settlement patterns in the colonial lesser kestrel. American Naturalist 169E000.

Serrano, D., Forero, M.G., Donázar, J.A., Tella, J.L., 2004. The role of dispersal and social attraction on colony dynamics of lesser kestrels. Ecology 85, 3438-3447.

Souza, F.L., Cunha, A.F., Oliveira, M.A., Pereira, G.A.G., Pinheiro, H.P., dos Reis, S.F., 2002. Partitioning of molecular variation at local spatial scales in the vulnerable neotropical freshwater turtle, Hydromedusa maximiliani (Testudines, Chelidae): implications for the conservation of aquatic organisms in natural hierarchical systems. Biological Conservation 104, 119-126.

Tella, J.L., 2001. Action is needed now, or BSE crisis could wipe out endangered birds of prey. Nature 410, 408.

Tella, J.L., Mañosa, S., 1993. Eagle owl predation on Egyptian vulture and northern goshawk: possible effect of a decrease in European rabbit availability. Journal of Raptor Research 27, 111-112.

Tella, J.L., Forero, M.G., Hiraldo, F., Donázar, J.A., 1998. Conflicts between lesser kestrel conservation and European Agricultural Policies as identified by habitat use analyses. Conservation Biology 12, 593-604.

Titeux, N., Dufrene, M., Jacob, J.P., Paquay, M., Defourny, P., 2004. Multivariate analysis of a fine-scale breeding bird atlas using a geographical information system and partial canonical correspondence analysis: environmental and spatial effects. Journal of Biogeography 31, 1841-1856.

Villafuerte, R., Viñuela, J., Blanco, J.C., 1998. Extensive predator persecution caused by population crash in a game species: the case of the red kites and rabbits in Spain. Biological Conservation 84, 181-188.

Whitfield, D.P., MacLeod, D.R.A., Watson, J., Fielding, A.H., Haworth, P.F., 2003. The association of grouse moor in Scotland with the illegal use of poisons to control predators. Biological Conservation 114, 157-163.

Whitfield, D.P., Fielding, A.H., Mcleod, D.R.A., Haworth, P.F., 2004. The effects of persecution on age of breeding and territory occupation in golden eagles in Scotland. Biological Conservation 118, 249-259. 